\title{
Growth hormone in short, slowly growing children and those with Turner's syndrome
}

\author{
C R BUCHANAN, C M LAW, AND R D G MILNER on behalf of the Health Services Human Growth \\ Hormone Committee, Institute of Child Health, London
}

SUMMARY Results of an aborted placebo controlled trial of treatment with human pituitary growth hormone in children with Turner's syndrome and short, slowly growing children are reported. One child in each group had a considerable reduction in growth rate standard deviation score while taking growth hormone. The remaining eight patients with Turner's syndrome and 10 short, slowly growing patients who received growth hormone showed mean rises in growth rate of greater than two standard deviation scores. Neither placebo group showed a mean increase in growth rate standard deviation score. These differences were significant.

Some short children who grow slowly and have normal serum concentrations of growth hormone during pharmacological provocation have been shown to increase their growth rate during treatment with growth hormone. ${ }^{1}$ Girls with Turner's syndrome have also shown improved growth during short periods of treatment with the hormone. ${ }^{2}$ Neither group of children has received growth hormone in a placebo controlled trial. Multicentre trials were therefore established and coordinated by the Health Services Human Growth Hormone Committee to find out if treatment with growth hormone could provoke a significant increase in their rates of growth.

\section{Patients and methods}

Turner's syndrome was diagnosed from chromosomal analysis of peripheral blood lymphocytes. Short, slowly growing children were selected who had a height for chronological age at least 2.5 standard deviations below the mean and a growth rate below the 25 th centile during the year before the trial. The standards for height and growth rate are those of Tanner et al. ${ }^{3}$ Bone ages estimated by the TW2 system were either delayed or concordant with chronological age. ${ }^{4}$ Children were excluded if they had been born prematurely ( $<37$ weeks' gestation), had had a birth weight below the 3rd centile for gestational age, or showed definite dysmorphic features.

No child in either group had received previous hormonal treatment. All patients were prepubertal as defined by Tanner ${ }^{5}$ and had normal endocrine function, except for some patients with Turner's syndrome who had raised gonadotrophin concentrations in serum. Each patient had achieved a growth hormone concentration greater than $15 \mathrm{mU} / \mathrm{l}$ on testing. Anthropometric measurements were recorded at the child's local growth centre at three monthly intervals for at least 12 months, or at about yearly intervals for at least three years before acceptance.

The trial design for both groups of patients was identical. Each child was allocated by a double blind random method to one of three groups, and the intended protocol was in three phases; group A were to receive growth hormone 4 IU thrice weekly by subcutaneous injection for 12 months; group B were to receive the same regimen of growth hormone for only six months, then placebo injections thrice weekly subcutaneously for six months; and group $\mathrm{C}$ were to receive placebo for six months then growth hormone for six months. All three groups were to be monitored for a further six months of no treatment.

The placebo was indistinguishable in appearance and presentation from growth hormone. Anthropometric measurements were performed at least every two months by the regular anthropometrist at each growth centre. Bone age was to be estimated at entry and six monthly thereafter.

Measurements of height and rate of growth are reported as standard deviation scores for age and sex according to Tanner et al. ${ }^{3}$ Standard deviation scores for height and rate of growth for the patients with Turner's syndrome were derived from data in published series of girls with Turner's syndrome who had not received hormone treatment. ${ }^{67}$ Rate of growth at entry was calculated from the preceding 
six months, or longer (maximum 1.3 years) when a recent measurement was not available. Consent was obtained from parents and any child over 12 years old.

Comparisons of the characteristics of the groups treated with growth hormone or placebo at entry into the trial and their respective standard deviation scores for growth rate were made by unpaired Student's $t$ test or Fisher's exact test. Differences in growth rate standard deviation score within each group were analysed by paired Student's $t$ test (one tailed or two tailed).

\section{Results}

Thirty patients with Turner's syndrome and 50 short, slowly growing children entered the trial from September 1984 onwards. The trial was stopped when growth hormone was withdrawn from use in the United Kingdom in May 1985 after early reports of the development of Creutzfeldt-Jakob disease in patients treated with growth hormone in the United States and United Kingdom. ${ }^{8}$ Fourteen patients with Turner's syndrome and 19 short, slowly growing children had completed 0.4 years or more of the first phase of the trial by that time. The results on these children from eight growth centres are presented (after exclusion of one boy in the short, slowly growing group taking growth hormone who progressed to pubertal stage 2, testicular volume $10 \mathrm{ml}$ each side, after six months of the trial). The growth hormone group represents patients in groups $\mathrm{A}$ and $\mathrm{B}$ and the placebo group and those in group $\mathrm{C}$ of the original protocol. These patients had not all completed the first six months of the study, hence bone age data are incomplete.

PATIENTS WITH TURNER'S SYNDROME

Seven subjects in the growth hormone group and one in the placebo group had a 45 XO karyotype, the remainder having chromosomal variants. This difference was not significant (Fisher's exact test). Table 1 outlines details of chronological age, height, growth rate standard deviation score at entry to the trial, and growth rate standard deviation score and bone age changes during treatment in the growth hormone and placebo groups. There were no significant differences at entry (Student's $t$ test, two tailed) although the mean growth rate standard deviation score of the Turner's syndrome placebo group $(+1 \cdot 1)$ was different from that of the growth hormone group. As these patients were assessed according to standards for Turner's syndrome, their mean growth rate standard deviation scores at entry should not have differed from zero. This difference would have been less marked if the growth rate standard deviation score at entry had been obtained over at least a full year-growth hormone group growth rate standard deviation score mean (SD) $-0.8(1.4)$; placebo group growth rate standard deviation score $-0 \cdot 1(1 \cdot 0)$-rather than six months, and the placebo group would not then have shown a significant fall in growth rate standard deviation score. The shorter interval was considered more appropriate for comparison with the six month period of treatment.

Figure 1 shows the individual changes in growth rate standard deviation score during the treatment period. Eight subjects receiving growth hormone showed an increase in growth rate standard deviation score (range $+0 \cdot 1$ to $+5 \cdot 5$, or growth rate -0.2 to $+4.5 \mathrm{~cm} /$ year). The ninth subject had a reduction of $3 \cdot 6$. The mean increment in growth rate standard deviation score of 1.7 for the group was significant $(p<0.05$, one tailed). Four girls receiving placebo showed a fall in growth rate standard deviation score (range -1.4 to -3.1 ), the fifth having a marginal reduction of 0.05 (group

Table 1 Patients with Turner's syndrome: chronological age, height, and growth rate at entry to trial and during trial

\begin{tabular}{|c|c|c|c|c|}
\hline & \multicolumn{2}{|c|}{$\begin{array}{l}\text { Growth hormone group } \\
(n=9)\end{array}$} & \multicolumn{2}{|l|}{$\begin{array}{l}\text { Placebo group } \\
(n=5)\end{array}$} \\
\hline & Mean (SD) & Range & Mean $(S D)$ & Range \\
\hline Chronological age (years) & $9 \cdot 81(2 \cdot 78)$ & $4 \cdot 42$ to $13 \cdot 35$ & $10 \cdot 22(2 \cdot 74)$ & $4 \cdot 13$ to 14.45 \\
\hline Height $(\mathrm{cm})$ & $116 \cdot 3(12 \cdot 0)$ & 92.4 to 133.3 & $113 \cdot 5(17 \cdot 4)$ & $85 \cdot 1$ to $132 \cdot 4$ \\
\hline \multicolumn{5}{|l|}{ Height standard deviation score } \\
\hline for chronological age & $-0.3(0.7)$ & -1.0 to +1.0 & $-0.9(0.7)$ & -1.8 to -0.2 \\
\hline Trial period (years) & $0.49(0.02)$ & 0.46 to 0.54 & $0.48(0.04)$ & 0.42 to 0.52 \\
\hline \multicolumn{4}{|l|}{ Growth rate at entry } & -0.4 to +2.4 \\
\hline \multicolumn{5}{|l|}{ Growth rate on treatment } \\
\hline (standard deviation score) & $1.4(1 \cdot 8)$ & $-2 \cdot 0$ to $+3 \cdot 3$ & $-0.7(1.8)$ & $-2 \cdot 0$ to $+2 \cdot 4$ \\
\hline${ }^{*}$ Bone age advancement & $1 \cdot 0 \dagger(0.6)$ & 0.2 to 1.7 & $1 \cdot 5 \ddagger(1 \cdot 1)$ & 0.8 to 2.7 \\
\hline
\end{tabular}

${ }^{*}$ Bone age advancement $=$ change in bone age/change in chronological age; $\nmid n=6 ; \neq n=3$. 


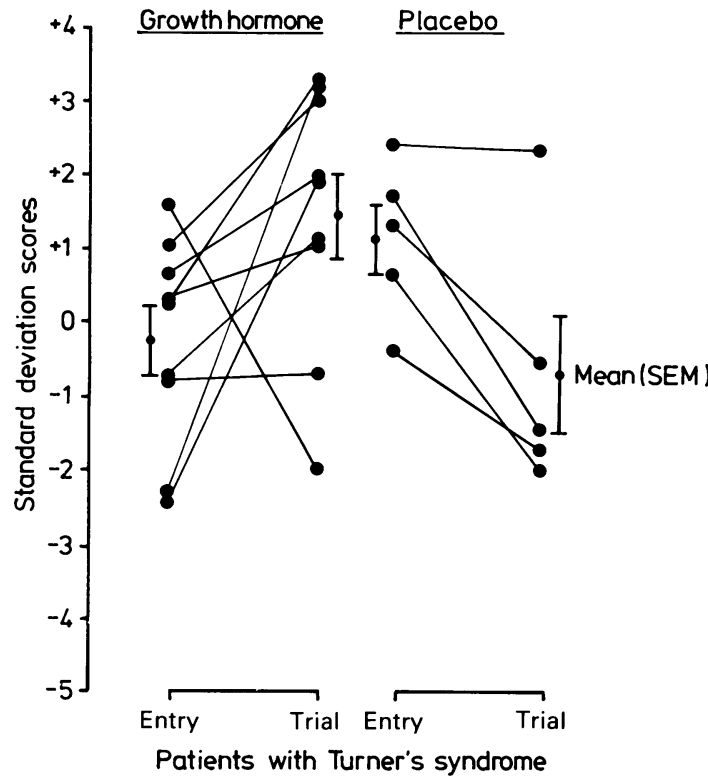

Fig. 1 Children with Turner's syndrome: growth rate scores at entry and during trial.

range -0.2 to $-2 \cdot 8 \mathrm{~cm} /$ year). The mean change of -1.8 with placebo was a significant fall $(\mathrm{p}<0 \cdot 05$, two tailed). Thus the mean increase in growth rate score during treatment with growth hormone was significantly different from the response of the placebo group $(\mathrm{p}<0 \cdot() 25$, one tailed)

The girl whose score changed by -3.6 differed significantly from the rest of her group. When she was excluded from the analysis both the mean change in growth rate standard deviation score $(+2 \cdot 4)$ in the remainder of the growth hormone group and the difference in response from the placebo group reached greater significance ( $p<0.005$, two tailed, and $<0.005$, one tailed, respectively).

Bone age at entry ranged from 3 to 12 'years' in both groups. The mean change in bone age during treatment with growth hormone was not inappropriate, but little can be inferred from such a short study period.

SHORT, SLOWLY GROWING CHILDREN

Table 2 outlines details of chronological age, height, growth rate standard deviation score at entry, and growth rate standard deviation score and changes in bone age during treatment of the growth hormone and placebo groups.

The mean age of the placebo group ( $11 \cdot 1$ years) was significantly higher $(p<0 \cdot 05$, two tailed) than that of the growth hormone group ( 7.6 years), which contained four children under 6 years old. Bone age ranged from 7.6 to 9.8 'years' in the placebo group and from $2 \cdot 0$ to 11.1 'years' in the growth hormone group. The mean heights of the two groups were significantly different $(p<0.05$, two tailed). Although initially selected for having a low growth rate (below the 25 th centile) over one year before acceptance, three children in each group had a higher growth rate than this by the time of entry. In turn, three children (two in the growth hormone group) had grown so well that they were no longer as short as 2.5 standard deviations below the mean for their height. The use of growth rate standard deviation score over the nearest whole year to entry (growth hormone group mean $-1 \cdot 1$, placebo group mean - 1.3) would not have significantly affected the following statistical analysis.

Figure 2 shows individual changes in growth rate standard deviation score during the treatment period. Nine of the growth hormone group showed an increase in growth rate standard deviation score

Table 2 Short, slowly growing children: chronological age, height, and growth rate at entry to trial and during trial

\begin{tabular}{|c|c|c|c|c|}
\hline & \multicolumn{2}{|c|}{$\begin{array}{l}\text { Growth hormone group } \\
(n=11: 9 \text { boys, } 2 \text { girls })\end{array}$} & \multicolumn{2}{|c|}{$\begin{array}{l}\text { Placebo group } \\
(n=7: 5 \text { boys, } 2 \text { girls })\end{array}$} \\
\hline & Mean $(S D)$ & Range & Mean $(S D)$ & Range \\
\hline Chronological age (years) & $7 \cdot 63(3 \cdot 25)$ & $2 \cdot 64$ to $12 \cdot 70$ & $11 \cdot 10(1 \cdot 08)$ & $10 \cdot 00$ to $13 \cdot 15$ \\
\hline Height $(\mathrm{cm})$ & $105 \cdot 3(15 \cdot 7)$ & $79 \cdot 3$ to $129 \cdot 3$ & $119 \cdot 6(5 \cdot 0)$ & $114 \cdot 1$ to $126 \cdot 7$ \\
\hline Height standard deviation score & & & & \\
\hline for chronological age & $-3 \cdot 1((0 \cdot 7)$ & $-2 \cdot 2$ to $-4 \cdot 3$ & $-3 \cdot 5(0.6)$ & -2.4 to -4.4 \\
\hline Trial period (years) & $0 \cdot 49(0 \cdot() 4)$ & 0.40 to 0.54 & $0.48(0.03)$ & 0.42 to 0.52 \\
\hline $\begin{array}{l}\text { Growth, rate at entry } \\
\text { (standard deviation score) }\end{array}$ & $-1 \cdot 1(1 \cdot 4)$ & $-3 \cdot 5$ to $+1 \cdot 5$ & $-0.9(1 \cdot 1)$ & -2.5 to +0.6 \\
\hline $\begin{array}{l}\text { Growth rate on treatment } \\
\text { (standard deviation score) } \\
{ }^{*} \text { Bone age advancement }\end{array}$ & $\begin{array}{l}0 \cdot 3(2 \cdot 0) \\
0 \cdot 9 \div(0 \cdot 5)\end{array}$ & $\begin{aligned}-4 \cdot 0 & \text { to }+3 \cdot 0 \\
0.2 & \text { to } 1.6\end{aligned}$ & $\begin{array}{r}-0.9(9 \cdot 2) \\
1.6 \neq(1.4)\end{array}$ & $\begin{aligned}-2.3 & \text { to }+1.3 \\
0.6 & \text { to } 3.6\end{aligned}$ \\
\hline
\end{tabular}

${ }^{*}$ Bone age advancement $=$ change in bone age/change in chronological age; $\neq \mathrm{n}=9 ;$; $=4$. 


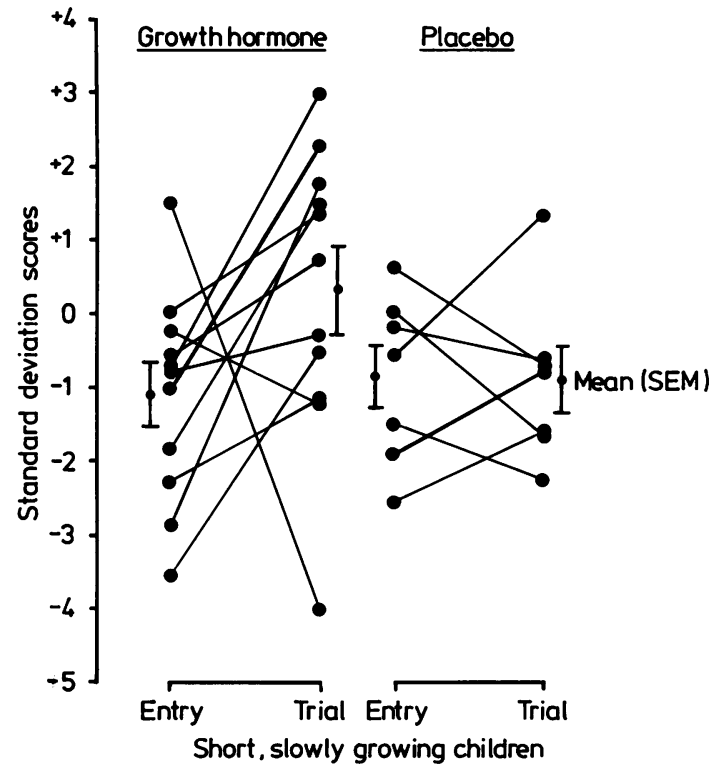

Fig. 2 Short, slowly growing children: growth rate scores at entry and during trial.

(range $+0 \cdot 5$ to $+4 \cdot 6$, or growth rate $+1 \cdot 1$ to $+3 \cdot 5$ $\mathrm{cm} /$ year), with two patients showing a decrease $(-1.0$ and -5.5 , or -1.9 and $-4.4 \mathrm{~cm} /$ year $)$, the mean change in score of +1.4 not reaching significance at the $5 \%$ level. Three children in the placebo group showed moderate increases and four showed decreases during treatment $(-1.7$ to +1.9 ; or -1.6 to $+1.4 \mathrm{~cm} /$ year). There was no change in the mean growth rate standard deviation score for this group. Thus the mean response from all subjects receiving growth hormone was not significantly different from that of the placebo group ( $p>0.05$, one tailed). As occurred with the group with Turner's syndrome, however, the child with the highest entry score to receive growth hormone had a response $(-5.5)$ significantly different from that of the remainder of the group and could be considered separately. His growth rate over 1.8 years had averaged the 25 th centile with a period of above average growth immediately before entry. When his response was excluded the remainder of the growth hormone group showed a mean rise of $+2 \cdot 1$ ( $<<0.005$, one tailed) which was significantly different from the mean placebo response $(\mathrm{p}<0.025$, one tailed).

\section{Discussion}

There was great disappointment among clinicians, parents, and children when these trials were halted prematurely. Important ethical issues were entailed to determine which further groups of children might benefit from treatment with growth hormone and whether it was justifiable to have a control group receiving placebo by a parenteral route. Some growth centres were unable to admit children to the study because local ethical committees refused to approve the use of a placebo controlled group. Nevertheless, recruitment was good owing to the enthusiasm of families attending other growth centres. Possible placebo effects on growth of an injection regimen such as that in this study have never to our knowledge been reported before. Inclusion of a placebo control group may improve the validity of using six month phases to reduce the length of a trial such as this. The potential unreliability of a six month measurement of growth rate rather than a whole year is recognised, and our results may reflect the tendency for regression to the mean over shorter intervals. Seasonal fluctuation may account for the -3.6 change in growth rate score observed for one subject in the Turner's syndrome growth hormone group. Her subsequent six monthly measurements without treatment showed swings of similar magnitude about the mean.

This trial was abandoned for reasons unconnected with its objectives. ${ }^{8}$ Statistical analysis of the limited unselected data thus remains valid. The findings provide further encouraging evidence that patients with Turner's syndrome might respond to treatment with growth hormone for six months or longer. The short, slowly growing children receiving growth hormone showed, with the exception of one boy, a significant mean rise in growth rate standard deviation score. This group of children is likely to be heterogeneous, ${ }^{1}$ and other studies are clearly essential to determine which children could benefit from treatment with growth hormone. A growth rate below the 25 th centile may not be helpful in selecting children for study: a higher centile would exclude children exhibiting catch up growth at the time of entry.

An important finding was the absence of an increase in the mean growth rate standard deviation score of either placebo group. The availability of biosynthetic growth hormone now permits the further trials that are necessary to establish how treatment with growth hormone might be of short or long term benefit to children with Turner's syndrome and those of short stature with normal growth hormone concentrations as defined by conventional criteria.

We thank the directors of the regional growth centres and their patients for their cooperation in the trials. 


\section{References}

' Rudman D, Kutner MH, Blackston RD, Cushman RA, Bain RP, Patterson JH. Children with normal-variant short stature: treatment with human growth hormone for six months. N Engl J Med 1981:305:123-31.

2 Rudman D, Goldsmith M, Kutner M, Blackston D. Effect of growth hormone and oxandrolone singly and together on growth rate in girls with $\mathrm{X}$ chromosome abnormalities. J Pediatr 1980;96:132-5.

3 Tanner JM, Whitehouse RH, Takaishi M. Standards from birth to maturity for height, weight, height velocity and weight velocity: British children 1965. Arch Dis Child 1966:41:454-71: 613-35.

4 Tanner JM, Whitehouse RH, Cameron N. Marshall WA. Healy MJR, Goldstein H. Assessment of skeletal maturity and prediction of adult height. 2nd ed. London: Academic Press. 1983.
5 Tanner JM. Growth at adolescence. 2nd ed. Oxford: Blackwell Scientific Publications, 1962.

- Lyon AJ, Preece MA. Grant DB. Growth curve for girls with Turner syndrome. Arch Dis Child 1985;60:932-5.

7 Ranke MB, Pfluger H. Rosendahl W, et al. Turner syndrome: spontaneous growth in 150 cases and review of the literature. Eur J Pediatr 1983:141:81-8.

${ }^{8}$ Powell-Jackson J, Weller RO, Kennedy P, Preece MA Whitcombe EM. Newsom-Davis J. Creutzfeldt-Jakob disease after administration of human growth hormone. Lancet 1985; ii:244-6.

Correspondence to Dr C R Buchanan, Department of Growth and Development, Institute of Child Health, London WC1N 1EH.

Received 13 March 1987 